\title{
Flame Spread Behaviour over Combustible Solid of Paper, Bagasse and Paper/Bagasse
}

\author{
Afifah Ramli ${ }^{1, *}$ Mohd Azahari Razali $^{2}$,Azwan Sapit ${ }^{2}$, Mohd Faisal Hushim ${ }^{2}$, Normayati \\ Nordin $^{2}$, Amir Khalid ${ }^{2}$ and Md Nor Anuar Mohammad ${ }^{2}$ \\ ${ }^{1}$ Faculty of Mechanical \& Manufacturing Engineering, UniversitiTun Hussein Onn Malaysia, 86400 \\ Pt. Raja, Batu Pahat Johor, Malaysia \\ ${ }^{2}$ Centre for Energy and IndustrialEnvironmentStudies (CEIES), Faculty of Mechanical \& \\ Manufacturing Engineering, Universiti Tun Hussein Onn Malaysia, 86400 Pt. Raja, Batu Pahat, \\ Johor, Malaysia
}

\begin{abstract}
Flame spread over combustible solid must be precisely identify in fire hazard and this is the basic problem in fire safety engineering field. To explore the flame spread mechanism over combustible solid, the downward flame spread behaviour over paper and bagasse has been investigated in this experiment. It found that the combustion pattern for paper was slightly different from the bagasse on the front view and this was analysed through the observation. The result also showed that the flame spread rate for paper is higher compared to the flame spread rate for bagasse. It seem that, although bagasse is the combustible solid the rate of flame spread is lower and the usage of bagasse can help to control the flame spread.
\end{abstract}

\section{Introduction}

Flame spread can described as the rate of movement crosswise a fuel surface and because the flame spread happen over a surface, enormous complications ascend which are not establish in simple gas-phase combustion problems [1]. So, flame spread behavior over combustible solid identified as a fundamental and an extremely dangerous occurrence in fire [2]. This is the purpose why it turn out to be important to understanding the flame spread behavior of this material. The examination that correlated to flame spread over combustible solid was the elementary problem in fire safety engineering field [3]. Previously, there are many researcher that concern to study the flame spread over combustible solid permitted to increase the capability of fire prevention.

The downward flame spread over polymethylmethacrylate (PMMA) [4] was scrutinized based on experimentally, computationally and analytically in an oxygen/nitrogen environment in normal gravity. It originate that the influence of ambient pressure on the spread rate and the alteration thickness seem only qualitatively, perhaps because of finiterate effects at low pressure. The flame spread over PMMA also examined experimentally in the quiescent air in an open space founded on the different thickness which is from 1.5 to 10 $\mathrm{mm}$ to discover flame spread mechanism over combustible materials. From this enquiry it

*Correspondingauthor: hd160083@siswa.uthm.edu.my 
seem that the flame spread rate growths with the reducing thickness of sheet and it tends to a continual value for thick sample. Then, it also scrutinized the width and thickness effects on flame spread over thermally-thin horizontal sample of PMMA [5]. The result indicated, as the width and thickness increase, convective heat transfer from the flame to the fuel surface decrease as additional air flow around the flame surface moves away from the pyrolysis area. In radiation condition, it increases as the size of flames increases while through conduction the fuel sample was measured and determined to have a negligible impact on flame spread.

Additionally, upward flame spread behavior over PMMA also examines by various number of width $100,200,300,400,500$, and $700 \mathrm{~mm}$ with the same thick and tall which is $18 \mathrm{~mm}$ and $1000 \mathrm{~mm}$ respectively [6]. The lateral diffusion throughout the flame width was proposed to grounds thicker flame along its centerline for wider flames and improve combustion competence. It indicated the flame spread rate was correlated to the width with a power of 0.35 . The downward flame spread behavior also forecast over thermally thin cellulose in a normal gravity quiescent environment [7]. It states that, one of the vital element to apprehension when it emanates to flame spread is the orientation of flame spread. It is because it be able to ensue in many ways which is by horizontally, vertically, upward or downward, and upside or underside. While the spread rate alteration radically from one orientation to another, it rests steady nonetheless.

Then, flame spread behavior over fabric also investigated based on the diverse weft thread angle as it is eminent that the natural fiber reveals different flame spread behavior compared to the synthetic fiber [8-9]. This study had been used combined fabric of kenaf/polyester, cotton/polyester and cotton/nylon. The result indicates that the flame spread rate for the combined fabric of kenaf and polyester enslavement on the angle as the angle is increasing from $0^{\circ}, 45^{\circ}$ and $90^{\circ}$ the flame spread rate are decreasing from $1.4702 \mathrm{~mm} / \mathrm{s}, 1.4579 \mathrm{~mm} / \mathrm{s}$ and $1.4122 \mathrm{~mm} / \mathrm{s}$ respectively. Not only for this material, the outcome for combined fabric of cotton/polyester and cotton/nylon also shown that both fabrics have comparable angle reliance where the flame spread rate decreases as the angle increases.

Next, it also had an investigated on downward flame spread towards paper based on the thickness from 0.4 to $10 \mathrm{~mm}$ [10]. Paper is one of the combustible solid and statistic data from Malaysia Fire and Rescue Department, about 5817 cases that involved in a building fire and one of the factors that contributed to this fire is paper [11]. The flame spread found to take place for sample thickness less than $8.4 \mathrm{~mm}$ under the condition of natural convection and the flame spread becomes unstable when the thickness is more than $8.4 \mathrm{~mm}$. It also investigated the flame spread behavior towards thin paper disk in narrow space and it was measured both upwards and downward flame spread [12]. This experiment agree that flame spread decrease when leading edge of the flame reaches $15-20 \mathrm{~mm}$ from the center of paper disk. The upward flame spread over corrugated cardboard [13] also explore and the result support that the non-homogeneity of the cardboard helped to reduce the acceleration of the upward spread rates by physically disorderly flow in the boundary layer close to the vertical surface and thereby modifying heating rates of the solid fuel above the pyrolysis region.

It seem that it important to investigated more about the flame spread behavior over paper but it is lack attention to study the flame spread towards paper. As known paper was produce from the pulp that derived from the wood and this production causes deforestation and the subsequent possibility of a limited timber resources crisis. Due to this awareness, many research had been conducted to produce paper by using natural fiber and the common natural fiber that use is banana fiber [14], palm fiber [15] and pineapple leaf fiber [16]s. Unfortunately, these studies have been conducted to study the properties of paper and focus on the mechanical properties of the paper only.

Instead of examine the flame spread behaviour over paper it is also significant to study the effect of natural fiber likes bagasse in combustion process as bagasse is one of the natural fiber that used in papermaking process in order to less the usage of wood pulp. The choose 
of bagasse in this experiment due to the number of cellulose, hemicellulose, lignin and small amount of extractives and mineral salts that compose from the bagasse [17]. In this context, the aim of this work is to test the flame spread behavior towards paper, bagasse and also the mixture of both materials as a main material used in papermaking process. At the end of this experiment the flame spread behavior also flame spread rate headed for both material will acknowledged. This study also important to know the effects of natural fibres which is bagasse influencing the behaviour of fire.

\section{Experimental Setup}

As mention above, this experiment has explored about the flame spread behavior towards combustible solid as in this experiment it used paper, bagasse and the mixture of this two materials. So, there are 3 specimen with pure paper, mixture of paper with bagasse and pure bagasse. The size for each specimen were same which is $10 \mathrm{~cm} \mathrm{x} 10 \mathrm{~cm}$ as the aim is to investigated the flame spread behavior based on this different material.

The specimen sheet were made from the A4 office recycled paper, bagasse and the mixture between this two materials. The bagasse has to be cleaned first to remove any dirt before bagasse will be soaked in hot water that has mixed with Sodium Hydroxide $(\mathrm{NaOH})$ for one day (24 hour) and this step also applied on recycle paper. Then, the mixture between this two materials will be blend at the same specified period rate which is 20 minutes. After that, the blended ingredient will placed on the net that are made from wooden frame. This step was seek to remove liquid contained in the material and let the sample sheet to dry at room temperature.

Then, all the specimen need to be examine by using Scanning Electron Microscope JEOL (SEM), to determine the structure of each specimen before the combustion testing. This specimen has testing with combustion testing in Vertical Flame Chamber and the schematics drawing for experiment arrangement as shown in Figure 1 below where the specimen was clamped to the holder. The camera was used to videotape the combustion process that occur during the experiment for all specimen until the end of the combustion process and it is videotape from the front view. The flame spread behavior that happens along the experiment had been analyzing through the videotape.

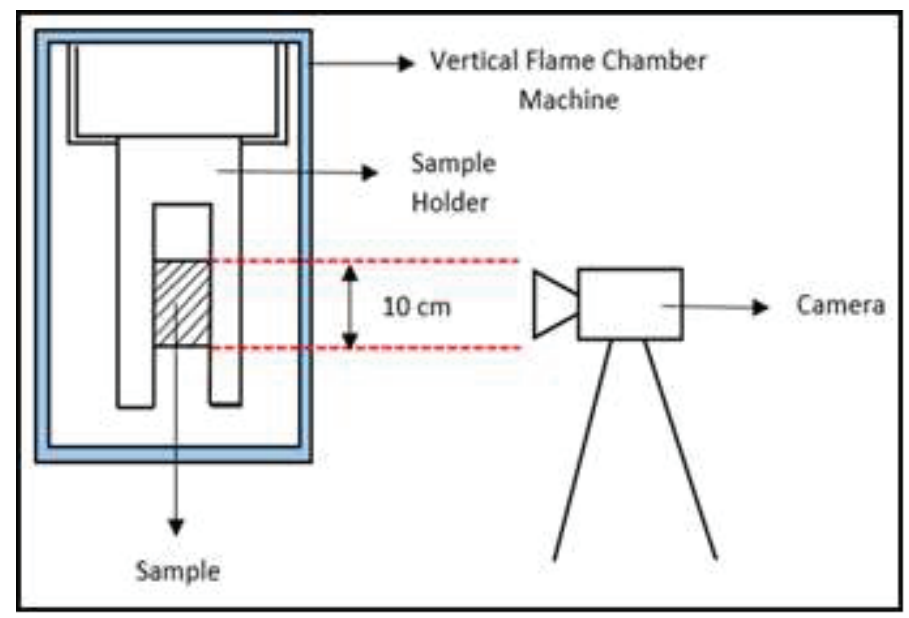

Figure 1: Schematics drawing for experimental setup 


\section{Result and Discussion}

\subsection{Flame Spread Behaviour}

In this experiment, the specimen is ignited at a point on its top edge where the flame spreads is in the downward direction. The comparison between the flames spread behavior that occur for each specimen can be seen in Figure 2 (a) to (c), that attached below as this result was videotaped to observe the flame spread behavior. The detail propagation of flame shape during the experiment can be seen in Figure 3 (a) to (c) below as this figure shows the shape of flame front for every $15 \mathrm{~s}$. The black line represents the combustion process while the red line represents the extinguished of flame.

From the result, it is known that flame spread for pure paper was the most stable and nearly consistent flame spread shape and combustion process occurred at the overall of the specimen. It started with "U" shape as showed in Fig. 3(a) below then slowly turned to "V" shaped. As the combustion process continued the flame spread behavior back to "U" shaped. As can be refer to Fig. 3(a), the propagation of the flame spread is limited to the central region at the beginning but after $45 \mathrm{~s}$ the flame spread take place at the whole of the specimen and behavior remained until the end of the specimen.

The result was significant different for the other type of specimen in term of flame spread behavior although at the beginning of ignition the flame spread started with " $U$ " pattern and this occurrence take place at each of specimen as showed in Fig. 3(a) to (c) below. For paper/bagasse specimen, the flame spread also take place at the whole of the specimen as shown in Fig. 3(b) below, but the flame spread shape for this specimen does not remained until the end of specimen. The flame spread shape become unstable after 150s and extinguished while the experiment is still carried out.

For the case of pure bagasse, it found that the flame spread shape becomes unstable and the flame is retarded after a few second in the very short period compared to paper/bagasse specimen, thus it is extinguished while the experiment was carried out as shown in Fig. 3 (c). The result seem that the usage of bagasse may influence on the flame spread shape.

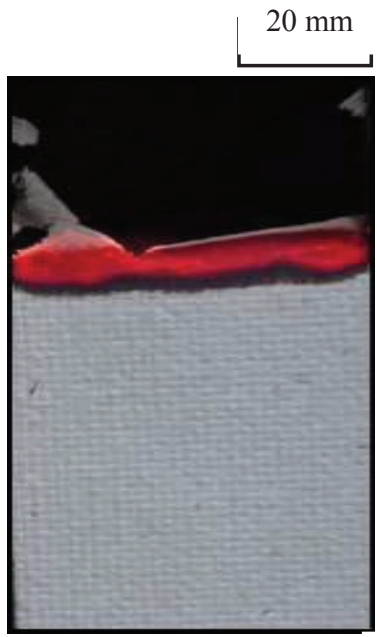

(a) Pure Paper

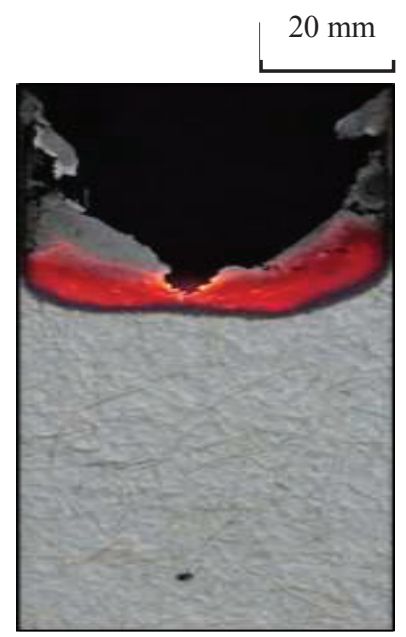

(b) Paper / Bagasse

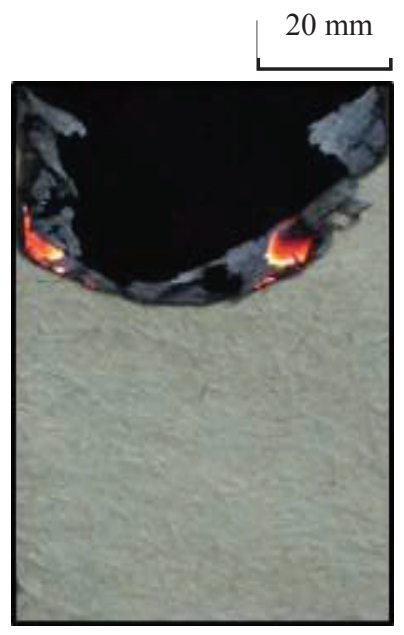

(c) Pure Bagasse

Figure 2: Flame spread behavior towards specimen 
- Flame

Extinguished flame

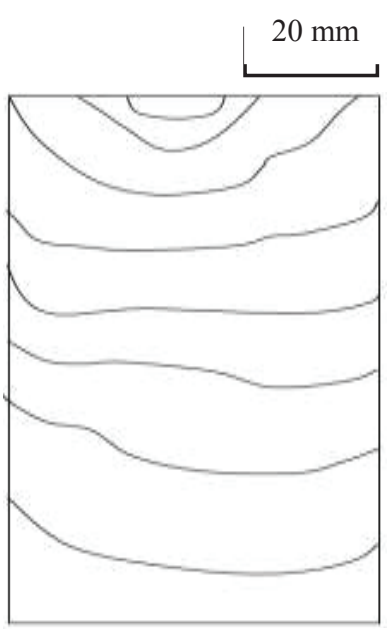

(a) Pure Paper

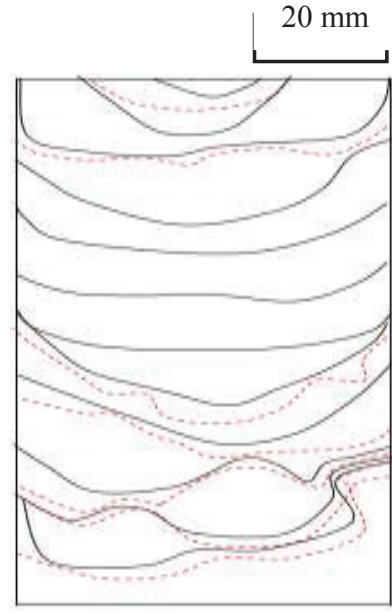

(b) Paper / Bagasse

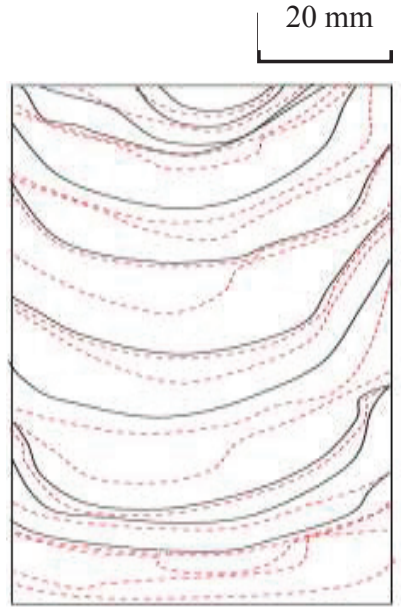

(c) Pure Bagasse

Figure 3: Overall flame spread behavior for specimen

\subsection{Flame Spread Rate}

Flame spread rates are obtained by measuring the position of the most preceding point of the burning front at each time. The flame spread rate for each specimen is different for each sample where the pure bagasse has the lower flame spread rate which is $0.4814 \mathrm{~mm} / \mathrm{s}$, follow by paper/bagasse specimen $0.5513 \mathrm{~mm} / \mathrm{s}$ and the higher flame spread rate goes to pure paper with $0.8133 \mathrm{~mm} / \mathrm{s}$ as shows in Figure 4 below. From this research, it is inferred that bagasse has significant impacts on the flame spread shape and also on the flame spread rate. However, the additional results are needed in order to examine about the influence of the material composition. This result will be useful to validate simulation works in the future. 


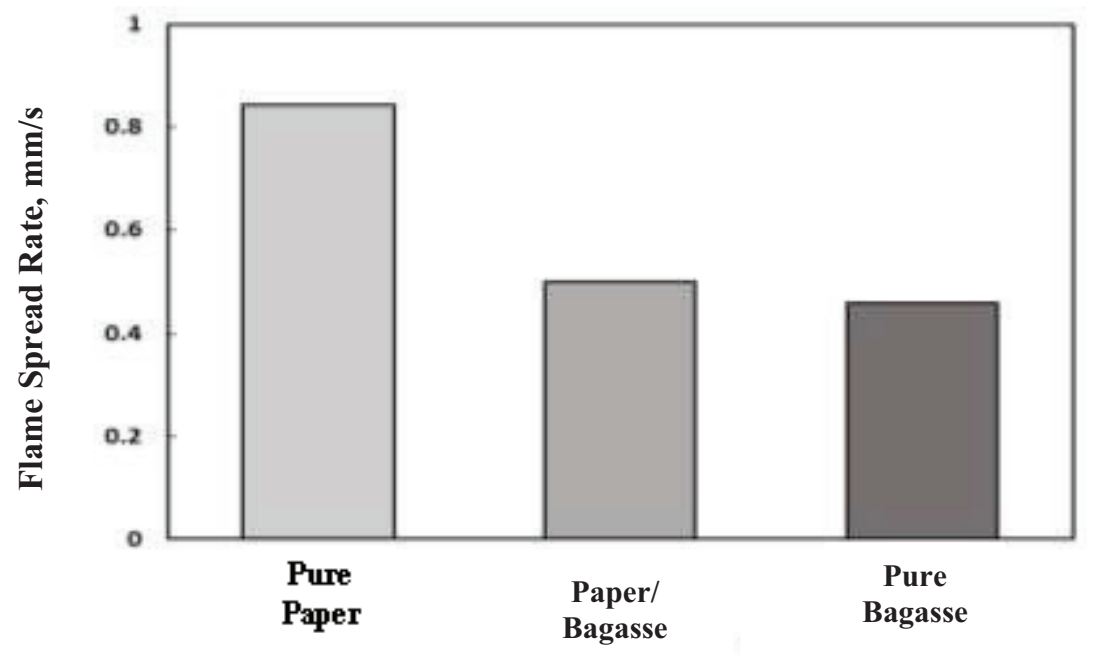

Type of sample

Figure 4: Flame spread rate for different type of specimen

Besides that, flame spread rate also influence by the size of the material fibre as shown in the Figure 5 below, it can see that the size of the paper fibre is trifling compare to bagasse fibre as the previous research specifies that the good distributive dispersion and the small particle size tend to result in a better flame retardancy [18]. From the experiment result it indicates that small size of fibre increase the flame spread rate as the flame spread rate for pure paper is the highest flame spread compared to specimen paper/bagasse and pure bagasse where the pure bagasse has the lower flame spread rate due to the hefty size of fibre.

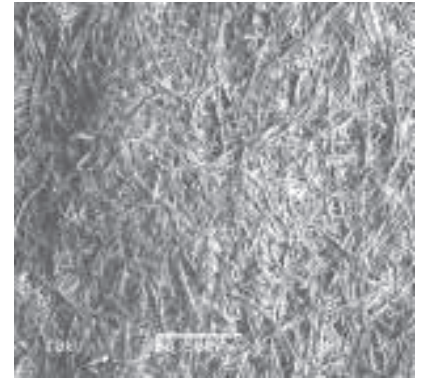

(a) Pure Paper

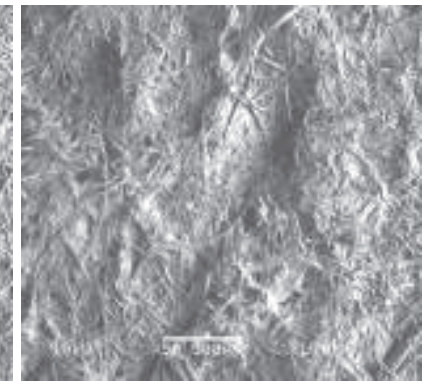

(b) Paper / Bagasse

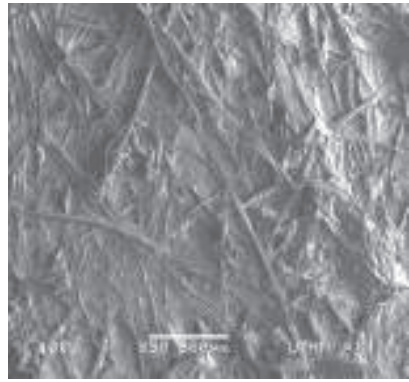

(c) Pure Bagasse

Figure 5: Microstructure image for different type of specimen 


\section{Conclusion}

Flame spread behavior for each specimen are different and the flame spread started to become unstable with the usage of bagasse. The usage of bagasse also made the flame often to extinguish during the combustion process while the flame of pure paper was stable and does not extinguish until the end of the combustion process. The usage of bagasse in this experiment found that this substance can be used in order to slow down the flame spread. As mentioned early, the flame spread rate for pure paper had the highest value of flame spread rate compared to pure bagasse that had the lowest flame spread rate. From the analysis, it found that the density value of the material also affected flame spread behavior and flame spread rate as the highest value of density the lower flame spread rate. From this experiment, it can say that substance with high density can use in order to control the flame spread.

\section{Acknowledgment}

The authors would like to thank Universiti Tun Hussein Onn Malaysia (UTHM) and Ministry of Higher Education Malaysia (MOHE) for their financial support of the present work through Fundamental Research Grant Scheme (FRGS-1465).

\section{References}

1. M. B. Ayani, J. A. Esfahani, and R. Mehrabian, "Downward flame spread over PMMA sheets in quiescent air: Experimental and theoretical studies," Fire Saf. J., 41, 164-169, (2006)

2. S. Charuchinda, M. Suzuki, and R. Dobashi, "Behavior of flames spreading downward over napped fabrics,'36, 313-325, (2001)

3. M. Azahari, A. Sapit, M. Faisal, and A. Khalid, "Flame Spread Behavior Over Combined Fabric Of Cotton / Polyester," 1-5, (1999)

4. K. K. Bhaskaran, M. D. King, S. Takahashi, T. Nagumo, and K. Wakai, "Downward Flame Spread Over Poly ( Methyl ) Methacrylate,”28, 2891-2897, (2000)

5. L. Jiang, C. H. Miller, M. J. Gollner, and J. Sun, "Sample width and thickness effects on horizontal flame spread over a thin PMMA surface," Proc. Combust. Inst., 36, 2987-2994, (2017)

6. K. Tsai, "Width effect on upward flame spread," Fire Saf. J.,44, 962-967, (2009)

7. S. Bhattacharjee, C. Paolini, W. Tran, J. Ray, and S. Takahashi, "ScienceDirect Temperature and CO 2 fields of a downward spreading flame over thin cellulose : A comparison of experimental and computational results," Proc. Combust. Inst., 35, 2665-2672, (2015)

8. M. Azahari, A. Sapit, A. N. Mohammed, M. Faisal,and H. Peraman, "Polyester Effect of Thread Angle on Flame Spread Behaviour over Combined Fabric of Kenaf / Polyester," 020016, (2017)

9. M. Azahari, K. Amir, M. Suzuki, W. Masuda, S. Hamidon, and S. Azwan, "Effect of Synthetic Material on Angle Dependency of Flame Spread Behavior over Combined Fabric," 020014, (2017)

10. M. Suzuki, R. Dobashi, and T. Hirano, "Behavior Of Fires Spreading Downward Over Thick Paper," 1439-1446, (1994)

11. JBPMWebsite (2013). JBPM Website Search. Retrieved on Disember 13, 2013 from:Searchhttp://www.bomba.gov.my/index.php/pages/view/542 (2013)

12. T. Takahashi, T. Daitoku, and T. Tsuruda, "Behavior of the flame spread along a thin paper-disk in a narrow space," Proc. Combust. Inst., 36, 3011-3017, (2017) 
13. M. J. Gollner, F. A. Williams, and A. S. Rangwala, "Upward flame spread over corrugated cardboard," Combust. Flame,158, 1404-1412, (2011)

14. A. Yosephine, V. Gala, A. Ayucitra, and E. S. Retnoningtyas, "Dalam Pembuatan Kertas Serat Campuran," 11, 94-100, (2012)

15. K. Syamsu, L. Haditjaroko, G. I. Pradikta, and H. Roliadi, "Campuran Pulp Tandan Kosong Kelapa Sawit dan Selulosa Mikrobial Nata de Cassava dalam Pembuatan Kertas,” J. Ilmu Pertan. Indones., 19, 14-21, (2014)

16. S. Wahab, "Producing Paper using Pineapple Leaf Fiber'", 390,3382-3386, (2012)

17. F. Mandelli, L. B. Brenelli, R. F. Almeida, R. Goldbeck, L. D. Wolf, Z. B. Hoffmam, R. Ruller, G. J. M. Rocha, A. Z. Mercadante, and F. M. Squina, "Simultaneous production of xylooligosaccharides and antioxidant compounds from sugarcane bagasse via enzymatic hydrolysis," Ind. Crop. Prod.,52, 770-775 (2014)

18. H. Huang, M. Tian, L. Liu, W. Liang, and L. Zhang, "Effect of Particle Size on Flame Retardancy of Mg ( OH ) 2 -Filled Ethylene Vinyl Acetate Copolymer Composites," Journal of Applied Polymer Science., 100, 4461-4469 (2006) 